\title{
Considerações sobre a coleta de Sphagnum no município de Cananéia, estado de São Paulo, Brasil ${ }^{1}$
}

\author{
Sheila Rancura ${ }^{2,4}$, Marcelo Martins Ribeiro ${ }^{3}$ e Nivaldo Nordi ${ }^{2}$
}

Recebido em 8/03/2009. Aceito em 6/11/2009

\begin{abstract}
RESUMO - (Considerações sobre a coleta de Sphagnum no município de Cananéia, Estado de São Paulo, Brasil). O manejo de espécies florestais não madeireiras é uma importante alternativa para a manutenção das florestas. Contudo, a demanda por algumas espécies em escala comercial pode resultar em impactos negativos sobre a biodiversidade local. As briófitas, particularmente espécies do gênero Sphagnum, estão entre os recursos vegetais explorados em áreas de restinga no município de Cananéia, litoral sul do Estado de São Paulo. A coleta das briófitas pela população local visa atender ao mercado de plantas ornamentais. Para avaliação da regeneração do Sphagnum foram instaladas parcelas e realizadas duas coletas simulando a forma de extração tradicional, que consiste na coleta manual e seletiva da camada superficial de Sphagnum com altura aproximada de $15 \mathrm{~cm}$. Foram medidas as variáveis altura, porcentagem de cobertura e rendimento do Sphagnum. Sob as condições encontradas no experimento de simulação da extração tradicional, os resultados indicaram que decorridos seis e sete meses após a coleta o Sphagnum apresentou altura e rendimento semelhantes à condição inicial. Tais resultados reforçam a percepção dos extrativistas de que há um intervalo ótimo para a realização de uma nova coleta de Sphagnum no mesmo local. Dessa forma, quando a coleta é realizada da forma tradicional, os impactos negativos da extração sobre o crescimento de Sphagnum tendem a ser minimizados. Palavras-chave: extrativismo, manejo sustentável, produtos florestais não madeireiros, restinga
\end{abstract}

ABSTRACT - (Considerations on harvesting Sphagnum in Cananéia municipality, São Paulo state, Brazil). The management of non-timber forest products is an important alternative for forest maintenance. Nevertheless, the demand for some species on a commercial scale may result in negative impacts for local biodiversity. Bryophytes, particularly species of the genus Sphagnum, are among the plant resources exploited in restinga areas of Cananéia, on the southern coast of São Paulo state, Brazil. The harvesting of bryophytes by the local population aims to supply the ornamental plant market. To assess Sphagnum regeneration, plots were established and two harvests were carried out simulating traditional harvesting, which consists of manual and selective harvest of the superficial Sphagnum layer of approximately $15 \mathrm{~cm}$. Height as well as percent cover and Sphagnum yield were measured. Under experimental conditions, the results demonstrated that six and seven months after harvest Sphagnum presented height and yield similar to the initial values. As suggested by the harvesters, there might be an optimal period of time between harvests. In this sense, harvesting practices in their traditional form tend to minimize the negative impacts on Sphagnum growth.

Key words: harvesting, non-timber forest products, restinga, sustainable management

\section{Introdução}

O manejo sustentável de espécies nativas é uma interessante alternativa para a manutenção e conservação das florestas. Porém, a demanda em escala comercial pode gerar pressões impactantes sobre a biodiversidade local. Tais impactos podem ser reduzidos com estudos que aprofundem o conhecimento sobre as espécies exploradas, tanto do ponto de vista biológico quanto econômico e social (Castro 2002). Neste sentido, as práticas locais de usos de recursos são consideradas valiosas para auxiliar no manejo das espécies, para o qual contribuem de forma fundamental o conhecimento adquirido e a memória dos habitantes (Berkes \& Folke 2000).

Segundo Berkes \& Folke (2000) a sustentabilidade implica nas inter-relações entre as dimensões ecológica, social e econômica, compreendidas como um sistema único, ecológico e social. Este sistema abrange os recursos biológicos, suas interações bióticas e abióticas, assim como o conjunto de conhecimentos e práticas locais que orientam e regulam os modos de obtenção dos recursos (Berkes 1999). Tais conhecimentos contribuem com o extrativismo manejado, o qual pode ser entendido como a gestão de um dado recurso baseada em um enfoque técnico-científico e/ ou em práticas tradicionais (Diegues 2002). Neste contexto, para a proposição de técnicas sustentáveis de exploração das espécies, além de aspectos sobre a sua autoecologia, como o estoque disponível, a taxa de incremento e a regeneração natural (Fantini et al. 1992), também devem ser considerados os aspectos relacionados ao conhecimento tradicional e as estratégias locais de uso do recurso (Ming et al. 2003; Diegues 1994).

A utilização das florestas pelo ser humano envolve uma enorme diversidade de espécies e recursos. Entre tais recursos estão os produtos florestais não madeireiros, que constituem o principal meio de subsistência para muitas comunidades. Estima-se que cerca de 500 milhões de pessoas que vivem nas florestas e nas redondezas, dependem desses produtos como componente essencial para seu sustento (Tewari \& Campbell 1996).

No litoral sul do Estado de São Paulo, entre os recursos vegetais explorados pela população do município de Cananéia, destacam-se algumas espécies de briófitas, especialmente as pertencentes ao gênero Sphagnum, denominadas localmente por "veludo". A exploração comercial desta briófita no município está relacionada ao mercado de plantas, sendo utilizada para a produção de mudas e arranjos florais, como substrato para viveiros e como material de embalagem para plantas enraizadas. A coleta de briófitas em

\footnotetext{
1 Parte da tese de Doutorado da primeira Autora

2 Universidade Federal de São Carlos, Departamento de Hidrobiologia, Laboratório de Ecologia Humana e Etnoecologia, São Carlos, SP, Brasil

3 Centro de Estudos Ecológicos GAIA Ambiental, Cananéia, SP, Brasil

4 Autor para correspondência: sheiladocanteiro@gmail.com
} 
áreas de restinga surgiu há cerca de 50 anos no município de Cananéia e desenvolveu-se de forma a atender ao mercado de plantas ornamentais. A compra das briófitas coletadas no município geralmente é realizada por intermediários, os quais posteriormente as revendem à atacadistas de grandes centros urbanos.

A exploração de recursos vegetais em áreas de vegetação de restinga possui legislação específica, que estabelece critérios para exploração dos recursos florestais não madeireiros (São Paulo 1998). Contudo, no município de Cananéia a extração passou a ser exercida legalmente em áreas licenciadas somente após a organização dos extrativistas em uma associação (Associação dos Manejadores e Produtores de Plantas Nativas da Estância de Cananéia - AMPEC, fundada em agosto de 2001).

Ecologicamente as briófitas desempenham um importante papel nos ecossistemas, pois abrigam uma vasta comunidade biótica e participam do processo de formação do solo, propiciando condições para o desenvolvimento de outras plantas e servindo como reservatórios de água e nutrientes (Díaz et al. 2005). Além de sua importância ecológica, as briófitas são amplamente utilizadas pelo ser humano como indicadores ambientais, como absorventes em derramamentos de óleo e também com finalidades terapêuticas (Rochefort 2000). Em relação ao uso comercial, destaca-se a utilização do gênero Sphagnum para a produção de energia (turfa) e no mercado de plantas (Díaz et al. 2005; Rochefort 2000).

O manejo de briófitas tem sido investigado principalmente em países que possuem turfeiras, como Canadá (Lavoie \& Rochefort 1996), Nova Zelândia (Buxton et al. 1996), Portugal, Austrália, Tasmânia e Chile (Díaz et al. 2005). A exploração de briófitas em escala comercial (principalmente do gênero Sphagnum) e os impactos tanto em nível específico quanto em nível sistêmico tem motivado uma série de estudos (Clymo \& Duckett 1986; Rochefort 2000; Rochefort et al. 2002; Gorham \& Rochefort 2003; Diaz et al. 2005; Staddon \& Dyke 2007) e o desenvolvimento de pesquisas que visam propor e analisar formas de manejo e de conservação das áreas exploradas (Buxton et al. 1996; Butller et al., 1998; Rojas \& Schlatter 2004; Schlatter \& Schlatter 2004; Blanco \& de la Balze 2004). Alguns estudos propõem ações restauradoras como transplantes de porções de Sphagnum e semeadura de esporos, outros sugerem alternativas para uma extração menos impactante como a coleta manual e a proibição de ferramentas e maquinário pesado para coleta e transporte. Pesquisas realizadas na Nova Zelândia demonstraram que a taxa de regeneração está associada ao grau de remoção dos musgos na área (Buxton et al. 1996). No entanto, as diferenças de ordem ambiental e social, regionais ou específicas, determinam diferentes estratégias a serem adotadas em propostas para o desenvolvimento de técnicas de manejo (Ming et al. 2003).

No presente estudo foram levantadas informações sobre as práticas locais de coleta de Sphagnum no município de Cananéia a fim de oferecer elementos que contribuam para a proposição de uma estratégia de manejo que contemple o uso e a conservação deste gênero. A altura do Sphagnum e o grau de cobertura do solo por esta briófita são usualmente observados pelos extrativistas na avaliação sobre a possibilidade de coleta num determinado local (Rancura 2009). De forma a relacionar as práticas locais com a determinação de parâmetros para o manejo de Sphagnum, foi elaborado um experimento de simulação da coleta praticada pelos extrativistas e avaliada a regeneração do Sphagnum após diferentes intervalos de tempo. O grau de regeneração do Sphagnum foi medido por meio da análise de dados sobre as variáveis altura das plantas, porcentagem de cobertura e rendimento por área. Variáveis como altura média das plantas, biomassa total e o percentual de cobertura do solo são os principais parâmetros analisados para avaliação do grau de regeneração do gênero Sphagnum (Clymo 1970; Hayward \& Clymo 1983; Buxton et al. 1996; Campeau \& Rochefort 1996). Esclarece-se que a finalidade deste estudo não é avaliar o crescimento do Sphagnum, mas sim realizar uma análise sobre os intervalos de tempo entre duas coletas num mesmo local a partir dos parâmetros utilizados pelos extrativistas para medir a regeneração.

\section{Material e métodos}

O presente estudo foi desenvolvido no município de Cananéia, situado no sudeste do Estado de São Paulo, na região do Vale do Ribeira. Esta região atualmente concentra a maior parte da Floresta Atlântica remanescente no Estado e é reconhecida internacionalmente por sua relevância para a conservação do Meio Ambiente, para o conhecimento científico e para a preservação de valores humanos e do saber tradicional. O clima do município de Cananéia é classificado como Tropical Chuvoso (Af, segundo a classificação de Koppen), com precipitação média do mês mais seco superior a 60 mm (CEPAGRI 2009). Em relação às condições de pluviosidade e temperatura no município de Cananéia durante o período de coleta de dados (ano de 2004), apenas os meses de junho e agosto apresentaram uma marcada redução na pluviosidade (Fig. 1).

Na ilha de Cananéia, local de realização do estudo, predominam a vegetação de restinga e os manguezais (Silveira 1952; Brizzoti et al. 2009). A vegetação de restinga é composta por um conjunto de comunidades vegetais fisionomicamente distintas, sob influência marinha e flúvio-marinha, distribuídas em mosaico e que ocorrem em áreas com grande diversidade ecológica (Sugiyama 1998). As restingas são de fundamental importância para a estabilização de dunas e mangues e para a manutenção da drenagem natural (Lamêgo 1974; Pfadenhauer 1978).

O delineamento experimental buscou simular a forma de extração tradicional do Sphagnum realizada pela comunidade local. Segundo informações obtidas por meio de entrevistas estruturadas (Neto, 2004), observações diretas e conversas informais (Mello 1995; Viertler 2002), a coleta praticada pelos extrativistas consiste na retirada manual e seletiva da camada superficial de Sphagnum com altura aproximada de $15 \mathrm{~cm}$ (Rancura 2009). As informações obtidas junto aos extrativistas durante as coletas consistiram no julgamento sobre o grau de regeneração do Sphagnum e a possibilidade de efetuar uma nova coleta no mesmo local.

Foram instaladas seis parcelas de $8 \times 15 \mathrm{~m}$, divididas em 12 sub-parcelas de $2 \times 5 \mathrm{~m}$, totalizando 72 sub-parcelas e área de $720 \mathrm{~m}^{2}$. Quatro parcelas foram instaladas em Floresta Baixa de Restinga (A1, A2, A4 e A5) e duas parcelas em Brejo de Restinga (A3 e A6). As áreas onde foram instaladas as parcelas foram escolhidas por diferirem fisionomicamente e por serem utilizadas para extração do Sphagnum. Cada parcela foi delimitada sobre uma mancha contínua de Sphagnum visando obter maior homogeneidade entre as sub-parcelas. Depois de delimitadas, as áreas correspondentes às parcelas estariam sujeitas apenas às coletas periódicas previstas no experimento. Porém, na parcela A2 o experimento foi violado e a parcela foi excluída das análises. 


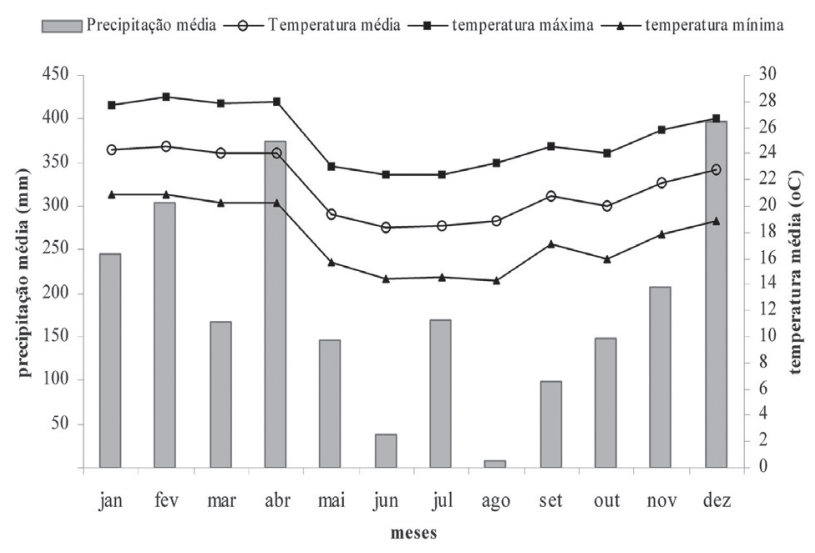

Figura 1. Precipitação e temperatura médias no município de Cananéia durante o ano de 2004 (Fonte: Boletins do Centro Integrado de Informações Agrometeorológicas do Estado de São Paulo - CIIAGRO/SP).

A caracterização das fisionomias vegetais das áreas onde foram instaladas as parcelas foi baseada em observações de campo, na Resolução CONAMA nº 07/1996 (que estabelece parâmetros básicos para análise dos estágios sucessionais da vegetação de Restinga para o Estado de São Paulo) e no diagnóstico realizado por Silva (1999). Os Brejos de Restinga são formações típicas de áreas abertas, com alta luminosidade ao nível do solo. Espécies herbáceas das famílias Cyperaceae e Poaceae são comumente encontradas. Há ocorrência de briófitas, especialmente do gênero Sphagnum e algumas espécies arbustivas, sobretudo de melastomatáceas. O substrato é arenoso e o lençol freático é raso, sendo que o solo está sujeito à saturação hídrica durante toda ou na maior parte do ano. Arbustos e árvores são raros e a quantidade de serapilheira acumulada é pequena ou ausente. A Floresta Baixa de Restinga possui fisionomia arbustivo-arbórea, com grande número de plantas com caules ramificados desde a base e predomínio de mirtáceas. Apresentam grande quantidade e diversidade de epífitas com destaque para as bromeliáceas, orquidáceas, aráceas, piperáceas, pteridófitas, briófitas e líquens. Os solos são predominantemente arenosos e possuem uma camada orgânica superficial com acúmulo de serapilheira. Em geral as condições de drenagem do solo são boas, ocorrendo inundações somente em alguns pontos. Devido ao sombreamento pelo dossel a luminosidade ao nível do solo é reduzida.

Foram efetuadas duas coletas em cada sub-parcela. A primeira coleta ocorreu no momento inicial, logo após a instalação do experimento. A segunda coleta somente foi realizada quando os extrativistas avaliaram que o Sphagnum presente na sub-parcela encontrava-se em condições de sofrer uma nova coleta. Desta forma, o intervalo de tempo entre as duas coletas variou entre as sub-parcelas, de acordo com o julgamento sobre a regeneração feito pelos extrativistas.

As variáveis altura, porcentagem de cobertura e rendimento foram mensuradas para avaliar o grau de regeneração do Sphagnum. No momento anterior à primeira coleta foram registrados os dados referentes à altura média (estimada a partir da medida do comprimento do Sphagnum em dez pontos aleatórios da sub-parcela) e porcentagem de cobertura (estimada visualmente a partir da área coberta por Sphagnum na sub-parcela, subdividida com fios de náilon em oito quadrantes iguais). Após registro dos valores de altura e porcentagem de cobertura foi realizada a primeira coleta, conforme a prática dos extrativistas, qual seja, retirada manual de aproximadamente $50 \%$ do Sphagnum com altura aproximada de 15 $\mathrm{cm}$. Depois de coletado, o Sphagnum passou pelo processo de beneficiamento praticado pelos extrativistas, que compreende a secagem ao sol e a retirada de galhos e folhas de outras espécies. Após o beneficiamento, o rendimento foi estimado da forma como é quantificado para a venda, isto é, acondicionado em sacos plásticos transparentes de 1,10 x 0,60 m. Cada saco com Sphagnum seco pesa em média $2,5 \mathrm{~kg}$. O procedimento adotado para a primeira coleta foi reproduzido no momento da segunda coleta. Conforme mencionado anteriormente, o intervalo de tempo entre a primeira e a segunda coleta variou entre as sub-parcelas, pois foi definido de acordo com a avaliação visual feita pelos extrativistas sobre a regeneração do Sphagnum em cada sub-parcela.
As seguintes espécies de Sphagnum foram encontradas no local de instalação das parcelas: S. perichaetiale Hampe, S. capillifolium (Ehrh.) Hedw, S. sparsum Hampe, S. palustre L. No entanto, para fins de análise foi considerado o gênero Sphagnum, pois os extrativistas não individualizam as espécies no momento da coleta.

Foram utilizados testes não paramétricos para análise dos dados devido à livre distribuição das amostras. Para analisar a regeneração do Sphagnum nas sub-parcelas foram avaliadas as diferenças entre as variáveis medidas nas duas coletas em cada sub-parcela, utilizando o teste de Wilcoxon (para dados pareados) com nível de significância igual a 1\%. Para avaliar o efeito dos diferentes intervalos de tempo sobre a regeneração, as amostras (agrupadas de acordo com o intervalo de tempo entre as duas coletas) foram comparadas por meio do teste de Kruskal-Wallis, com nível de significância alfa igual 1\%, seguido pelo teste de comparações múltiplas de Dunn (com correção de Bonferroni e nível de significância igual a 0,001). O teste de Kruskal-Wallis realiza comparações de amostras independentes e o teste de Dunn realiza comparações múltiplas entre as amostras e as agrupa de acordo com suas semelhanças (Zar 1996). As análises estatísticas foram realizadas com auxílio do software XLStat 2007.

\section{Resultados}

A avaliação realizada pelos extrativistas sobre a regeneração do Sphagnum indicou variação do intervalo de tempo entre as duas coletas para cada tipologia vegetacional e para as sub-parcelas. No Brejo de Restinga prevaleceram os intervalos de seis e 10 meses entre as duas coletas registrados em 50,0\% e 41,7\% das sub-parcelas instaladas nessa fisionomia, respectivamente. Na Floresta Baixa de Restinga prevaleceram os intervalos de sete e 11 meses, registrados em $66,7 \%$ e $22,2 \%$ das sub-parcelas referentes a essa fisionomia, respectivamente.

Devido ao reduzido número de sub-parcelas onde foram registrados os intervalos de oito e 12 meses (no Brejo de Restinga) e 10 meses (na Floresta Baixa de Restinga), tais amostras não foram consideradas nas análises estatísticas. Desta forma, os intervalos de seis meses e de 10 meses entre as duas coletas correspondem aos resultados das parcelas localizadas em Brejo de Restinga. Os intervalos de sete e de 11 meses entre duas coletas são referentes às parcelas localizadas em Floresta baixa de Restinga (Tab.1).

Considerando a altura média do Sphagnum, os dados indicam que os intervalos de seis, sete, 10 e 11 meses entre as duas coletas não foram suficientes para a regeneração completa em altura, dado que a altura média referente à segunda coleta é menor que a altura média inicial para todos os intervalos. Os valores de altura média de Sphagnum foram maiores nas parcelas localizadas no Brejo de Restinga (seis e 10 meses). As maiores diferenças em altura ocorreram nos intervalos de 10 e 11 meses entre as duas coletas. Contudo as diferenças foram significativas apenas para o intervalo de 10 meses (teste de Wilcoxon, $\mathrm{P}<0,01$ ) (Fig. 2).

Considerando a porcentagem de cobertura do solo por Sphagnum, a regeneração foi mais favorável nas parcelas localizadas na Floresta Baixa de Restinga, quando comparadas às parcelas localizadas no Brejo de Restinga. Após sete meses, a porcentagem média de cobertura por Sphagnum foi semelhante à observada antes da primeira coleta. Após 11 meses houve um aumento na porcentagem 
Tabela 1. Parcelas e sub-parcelas consideradas nas análises estatísticas.

\begin{tabular}{|c|c|c|c|}
\hline Parcela & Tipologia vegetacional & Intervalo entre as duas coletas & Número de sub-parcelas consideradas nas análises estatísticas \\
\hline A1 & Floresta baixa de Restinga & 11 meses & 8 \\
\hline A3 & Brejo de Restinga & 10 meses & 10 \\
\hline A4 & Floresta baixa de restinga & 7 meses & 12 \\
\hline A5 & Floresta baixa de Restinga & 7 meses & 12 \\
\hline A6 & Brejo de Restinga & 6 meses & 12 \\
\hline
\end{tabular}

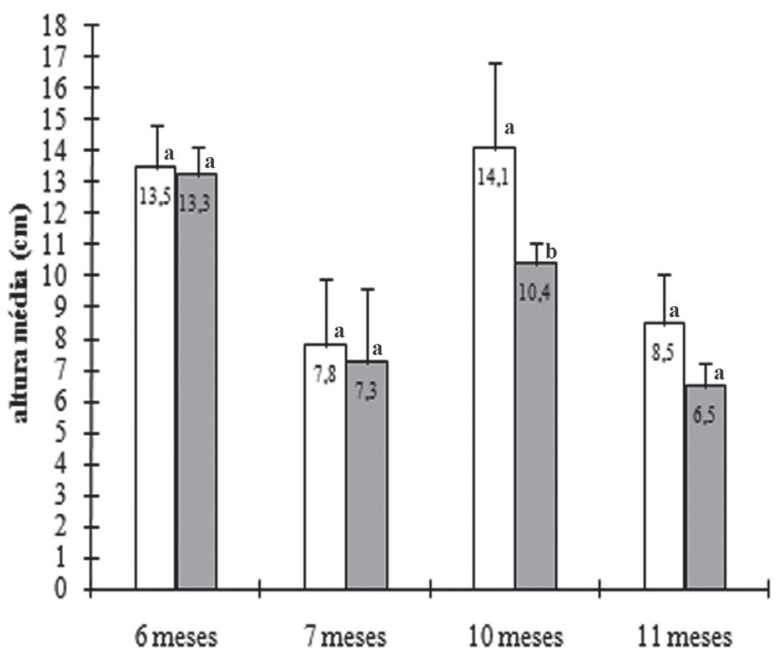

Figura 2. Altura média do Sphagnum na primeira e segunda coleta para os diferentes intervalos de tempo entre as duas coletas. Os intervalos de seis e 10 meses correspondem aos resultados para Brejo de Restinga e os intervalos de sete e 11 meses correspondem aos dados de Floresta baixa de Restinga. Médias seguidas da mesma letra em cada intervalo não diferiram significativamente entre si (teste de Wilcoxon, $\mathrm{p}<0,01)$. Primeira coleta $=\square$; segunda coleta $=\square$.

de cobertura em relação aos valores medidos antes da primeira coleta. Para a porcentagem de cobertura, assim como observado para a variável altura média, as maiores diferenças (apesar de não serem significativas) foram encontradas no período de 10 meses, nas parcelas localizadas em Brejo de Restinga (Fig. 3).

Considerando o rendimento médio as maiores diferenças ocorreram nos intervalos de 10 e 11 meses após a primeira coleta. Porém, diferenças significativas (teste de Wilcoxon, $\mathrm{P}<0,01)$ foram encontradas apenas para o intervalo de 10 meses entre as duas coletas (Fig. 4). Cabe ressaltar que a heterogeneidade dos valores de rendimento (alto desvio padrão) pode ter sido influenciada pela forma de quantificá-lo e pelo grau de umidade do Sphagnum.

Considerando a influência dos diferentes intervalos de tempo sobre a regeneração, o teste de Kruskal-Wallis indicou diferenças significativas para as variáveis altura média e rendimento médio entre os diferentes intervalos de tempo. O teste de Dunn apontou semelhanças na variável altura média para os intervalos de seis e sete meses entre as duas coletas, diferenciando este grupo dos intervalos de 10 e 11 meses. O mesmo agrupamento foi observado com

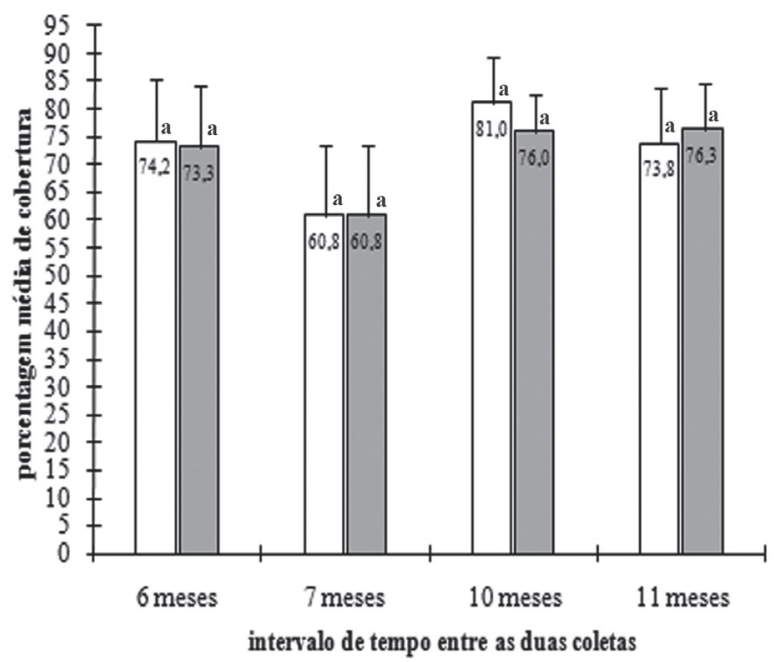

Figura 3. Porcentagem média de cobertura por Sphagnum na primeira e segunda coleta para os diferentes intervalos de tempo entre as duas coletas. Os intervalos de seis e 10 meses correspondem aos resultados para Brejo de Restinga e os intervalos de sete e 11 meses correspondem aos dados de Floresta baixa de Restinga. Médias seguidas da mesma letra em cada intervalo não diferiram significativamente entre si (teste de Wilcoxon, $\mathrm{p}<0,01$ ). Primeira coleta $=\square$; segunda coleta $=\square$.

respeito ao rendimento médio. Para a porcentagem média de cobertura, o teste de Kruskal-Wallis não indicou diferenças significativas em nenhum dos intervalos.

\section{Discussão}

Os resultados apresentados indicam que determinados intervalos de tempo entre duas coletas num mesmo local podem ser mais favoráveis à regeneração do Sphagnum, no que se refere às variáveis medidas. Tal indício também foi sugerido pelos extrativistas. Segundo informações levantadas entre os extrativistas (Rancura 2009), o Sphagnum cresce até uma altura máxima e após a estabilização da altura, a camada que se encontra abaixo da superfície do tapete de Sphagnum é abafada pelos musgos da camada superficial. Esta camada mais profunda entra em processo de decomposição, tornando-se inviável para a comercialização. Realizando a coleta seletiva e controlada, a camada mais superficial é retirada e os musgos das camadas inferiores tornam a crescer. Neste sentido, a regeneração de Sphagnum pode ter sido favorecida nas parcelas onde os intervalos entre as duas coletas foram de seis e sete meses. 


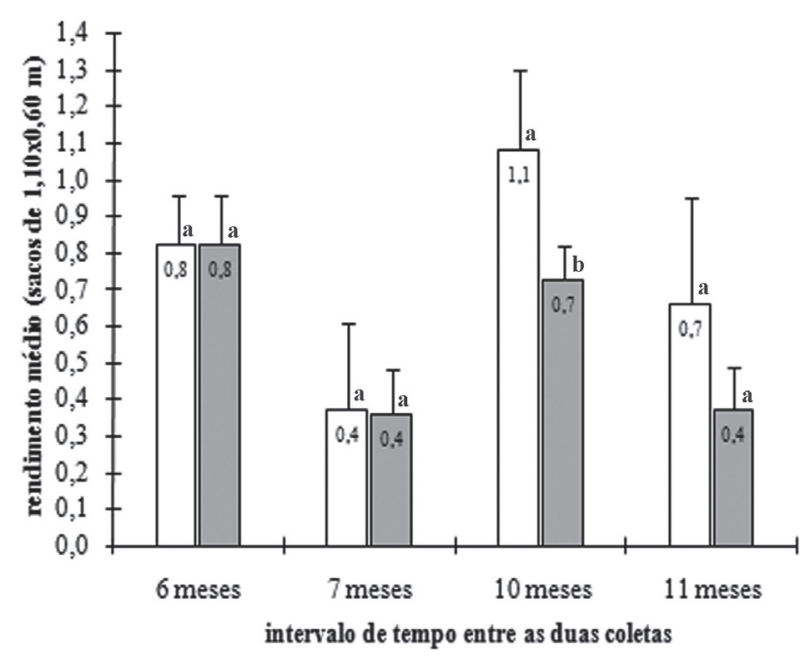

Figura 4. Rendimento médio do Sphagnum na primeira e segunda coleta para os diferentes intervalos de tempo entre as duas coletas. Os intervalos de seis e 10 meses correspondem aos resultados para Brejo de Restinga e os intervalos de sete e 11 meses correspondem aos dados de Floresta baixa de Restinga. Médias seguidas da mesma letra em cada intervalo não diferiram significativamente entre si (teste de Wilcoxon, $\mathrm{p}<0,01$ ). Primeira coleta $=\square$; segunda coleta $=\square$.

Em relação à avaliação sobre a regeneração realizada pelos extrativistas durante o exercício da coleta, é importante salientar que se trata de uma análise que possui a flexibilidade condizente com a complexidade dos elementos que podem influenciar a regeneração. Desta forma, a variabilidade encontrada nos resultados deriva, em parte, das variações encontradas em cada local de coleta.

Mesmo em condições ambientais distintas das encontradas neste estudo, há correlação entre a coleta e a regeneração do Sphagnum (Buxton et al. 1996). Experimentos realizados na Nova Zelândia demonstraram a tendência de um processo mais acelerado de regeneração, tanto em altura quanto em biomassa, em áreas que sofreram coleta do que em áreas onde o Sphagnum não foi coletado. No experimento conduzido por Buxton et al. (1996), a regeneração do Sphagnum ocorreu de forma mais acelerada nos primeiros 16 meses (para áreas de clima temperado com verão seco, fatores que limitam e reduzem a velocidade de crescimento). Em tais experimentos observou-se também uma correlação positiva entre o crescimento de Sphagnum em altura e a intensidade de coleta (Buxton et al. 1996). Desta forma, diferentes intervalos de tempo entre duas coletas no mesmo local podem ter influências distintas sobre a regeneração. Os dados referentes às coletas realizadas após 10 e 11 meses sugerem uma tendência à diminuição no rendimento e na altura média do Sphagnum e podem indicar que o tempo para a realização de uma nova coleta foi ultrapassado.

Além de ser afetada pelo intervalo de tempo entre duas coletas no mesmo local, a regeneração de Sphagnum também é influenciada pelas condições microambientais. Em uma das parcelas localizadas em Brejo de Restinga (A6), decorridos seis meses após a primeira coleta, os dados indicaram que o Sphagnum presente na parcela apresentou altura e rendimen- to semelhantes à condição inicial. Já para a tipologia Floresta de Restinga, não houve nova coleta antes de sete meses. É possível que algumas condições encontradas em Brejo de Restinga tenham favorecido a regeneração do Sphagnum.

A disponibilidade de água é indicada como um dos fatores mais importantes para o crescimento de Sphagnum e está relacionada com a distribuição das chuvas, com a evaporação e com o nível do lençol freático (Clymo \& Reddaway 1971; Gignac \& Vitt 1990). O nível do lençol freático é apontado como o principal fator limitante do crescimento de Sphagnum (Buxton et al. 1996; Clymo 1973; Hayward \& Clymo 1983; Campeau \& Rochefort 1996) e certa quantidade de água ao nível do solo, sem que haja submersão completa do tapete de Sphagnum, seria o mais adequado ao crescimento. No presente experimento, os locais escolhidos estavam sujeitos a condições semelhantes de pluviosidade e temperatura. Os elementos passíveis de maiores alterações seriam o nível do lençol freático e a evaporação, de acordo com a tipologia vegetacional dos locais onde as parcelas foram instaladas, i.e., Brejo de Restinga, com afloramento do lençol freático e alto índice de luminosidade ao nível do solo e Floresta Baixa de Restinga, ambiente sombreado e com lençol freático menos raso.

O grau de sombreamento é outro fator relevante para o crescimento de Sphagnum (Hayward \& Clymo 1983; Campeau \& Rochefort 1996; Buxton et al. 1996). Em relação ao sombreamento, Buxton et al. (1996) sugerem que locais com alta ou média intensidade luminosa e com $5 \%$ a $20 \%$ de sombreamento pelo dossel, a regeneração é mais rápida. Além disso, a localização do Sphagnum em superfícies planas, com nível de lençol freático relativamente estável, também favorece o crescimento (DPIW 2007). Estas condições são características da tipologia Brejo de Restinga e este ambiente pode se constituir como o mais propício à regeneração de Sphagnum.

Segundo Buxton et al. (1996) o crescimento em altura também pode estar relacionado com o grau de umidade e dessecação, variando de acordo com as estações do ano e diminuindo quando a taxa de dessecação se eleva. Esta constatação foi corroborada por estudos realizados na Tasmânia, os quais indicam que locais com alta pluviosidade, baixa evaporação e terrenos mal drenados, são particularmente favoráveis ao crescimento de Sphagnum (DPIW 2007). De acordo com os boletins do Centro Integrado de Informações Agrometeorológicas do Estado de São Paulo (CIIAGRO/ SP), a ilha de Cananéia não possui período seco e as maiores taxas de precipitação ocorrem entre novembro e março. A correlação positiva entre precipitação e crescimento do Sphagnum também foi apontada pelos extrativistas, segundo os quais o período mais propício para o crescimento é o verão, com um tempo médio de regeneração de três a oito meses (Rancura 2009).

A manutenção da vegetação nas áreas de ocorrência de Sphagnum gera uma proteção natural contra dessecamento e influi positivamente na sua regeneração (Buxton et al. 1996; 
DPIW 2007). Da mesma forma, protocolos para o manejo sustentável orientam a manter pelo menos $30 \%$ da cobertura de Sphagnum nos pontos de coleta e deixar uma superfície plana, de forma que o musgo restante esteja próximo ao nível da água. A resemeadura (Buxton et al. 1996; Campeau \& Rochefort 1996), relacionada com o crescimento vegetativo, indica que a dispersão das sobras de Sphagnum sobre o terreno contribui para a diminuição do tempo necessário para a regeneração. Entre as intervenções que devem ser evitadas ou controladas estão o corte da vegetação, o uso de maquinário, a drenagem e o pisoteio do terreno e a abertura de estradas nas áreas de ocorrência de Sphagnum e locais vizinhos.

Sob as condições encontradas nos locais de implantação das parcelas e realizando a coleta de acordo com os parâmetros tradicionais, os dados indicaram que decorridos seis e sete meses após a coleta, o Sphagnum apresentou altura e rendimento semelhantes à condição inicial. A regeneração de Sphagnum indicada pelos resultados ocorreu em um intervalo de tempo menor que o encontrado em outros experimentos, como na Nova Zelândia, onde os intervalos entre as coletas são de dois a três anos (Buxton et al. 1996). Porém, cabe ressaltar que as condições ambientais locais como alta luminosidade, baixa altitude, alta pluviosidade e lençol freático raso são, por si só, favoráveis ao crescimento de Sphagnum e podem ter contribuído para uma regeneração tão rápida quanto à indicada pelos resultados.

A forma de realização da coleta, o tempo decorrido entre duas coletas no mesmo local e as condições microambientais presentes em cada parcela podem ser apontadas como fatores condicionantes da regeneração. Da mesma forma que uma coleta predatória afeta negativamente a regeneração de Sphagnum, uma coleta adequada pode contribuir para uma regeneração mais rápida. O manejo adotado tradicionalmente pela população local tem correspondência nas medidas indicadas para diminuir os impactos negativos da extração sobre o crescimento de Sphagnum. Desta forma, as variáveis medidas tendem a apresentar menores diferenças quando o intervalo entre duas coletas é de seis e sete meses, apesar de as médias obtidas na segunda coleta quase sempre apresentarem valores menores.

Ressalta-se que a avaliação sobre a regeneração está sujeita à variabilidade microambiental encontrada em cada ponto de coleta. Desta forma, experimentos sobre o crescimento do Sphagnum e o acompanhamento da regeneração com o monitoramento de um maior número de variáveis são necessários para que os indícios levantados neste estudo sejam verificados.

\section{Agradecimentos}

Aos extrativistas do município de Cananéia, pelo aprendizado; à Dra. Olga Yano (Instituto de Botânica de São Paulo) pela identificação das espécies, aos Drs. Dalva Maria da Silva Matos (Universidade Federal de São Carlos), Maria Inês Salgueiro Lima (Universidade Federal de São Carlos), Nivaldo Lemes da Silva Filho (Universidade de Sorocaba) e Rosemary Oliveira (Instituto Chico Mendes de Conservação da Biodiversidade) pelas sugestões numa versão preliminar deste trabalho, à Coordenação de
Aperfeiçoamento de Pessoal de Nível Superior (CAPES) pela concessão da bolsa de estudos à primeira autora e à Fundação de Amparo à Pesquisa do Estado de São Paulo (FAPESP) pelo apoio financeiro à pesquisa.

\section{Referências bibliográficas}

Berkes, F. 1999. Sacred ecology. Traditional ecological knowledge and resource management. Nova York: Cambridge University Press.

Berkes, F. \& Folke, C. 2000. Linking social and ecological systems. New York, Cambridge University Press.

Blanco, D.E. \& de la Balza, V.M. 2004. Los turbales de la Patagonia, bases para su inventario y la conservación de su biodiversidad. Publicación $\mathrm{N}^{\circ} 19$, Wetlands International, Buenos Aires, Argentina.

Butller, A.; Grosvernier, P. \& Matthey, Y.1998. Development of Sphagnum fallax diaspores on bare peat with implications for the restoration of cut-over bogs. Journal of Applied Ecology 35: 800-810.

Brizzotti M. M; Faria, M. B. B. C.; Oliveira, A. A. 2009. Atlas dos remanescentes dos ecossistemas de restinga do complexo estuarino lagunar de Iguape, Ilha Comprida e Cananéia, litoral sul do Estado de São Paulo: Resultados preliminares. Pp.2621-2628. In: Anais XIV Simpósio Brasileiro de Sensoriamento Remoto, Natal, Brasil, INPE.

Buxton, R.P.; Johnson, P.N. \& Espie, P.R. 1996. Sphagnum Research Programme: The ecological effects of commercial harvesting. Science for Conservation 25: 1173-2946.

Campeau, S. \& Rochefort, L. 1996. Sphagnum regeneration on bare peat surfaces: field and greenhouse experiments. The Journal of Applied Ecology 33(3): 599-608.

Castro, R.C. F. 2002. Analise econômica do manejo de caixeta- Tabebuia cassinoides (Lam.) DC na região do Vale do Ribeira-SP: um estudo de caso. Dissertação de Mestrado. Escola Superior de Agricultura Luís de Queiroz. ESALQ/USP Piracicaba.

Centro de Pesquisas Meteorológicas e Climáticas Aplicadas à Agricultura (CEPAGRI). 2009. Clima dos Municípios Paulistas. http://www. cpa.unicamp.br/outras-informacoes/clima-dos-municipios-paulistas. html (acesso em 20/01/2009).

Centro Integrado de Informações Agrometeorológicas do Estado de São Paulo (CIIAGRO). 2009. Boletins do Centro Integrado de Informações Agrometeorológicas do Estado de São Paulo. http:// www.ciiagro.sp.gov.br/ciiagroonline/ (acesso em 05/01/2009).

Clymo, R. S. 1970. The growth of Sphagnum: methods of measurement. The Journal of Ecology 58(1): 13-49.

Clymo, R.S. \& Reddaway, E.J.F. 1971. Growth rate of Sphagnum rubellum Wils. on Pennine blanket bog. Journal of Ecology 62:191-196.

Clymo, R. S. 1973. The growth of Sphagnum: some effects of environment. The Journal of Ecology 61 (3): 849-869.

Clymo, R.S.\& Duckett, J.G. 1986. Regeneration of Sphagnum. New phytologist 102: 589-614.

CONAMA. Conselho Nacional do Meio Ambiente (Brasil). 1996. Resolução CONAMA n ${ }^{0}$ 7, de 23 de julho de 1996. Aprova parâmetros básicos para análise dos estágios de sucessão de vegetação de restinga para o Estado de São Paulo. Diário Oficial da União. Brasília.

Díaz, M.F.; Zegers, G. \& Larraín, J. 2005. Antecedentes sobre la importancia de las turberas y el pompoñ en la Isla de Chiloé. Fundación Senda Darwin, CASEB, Chile. http://www.sendadarwin. cl/materialdedescarga/Turberas.pdf (acesso em 23/10/2007).

Diegues, A. C. 1994. O mito moderno da natureza intocada. São Paulo: NUPAUB - Universidade de São Paulo.

Diegues, A.C. 2002. Aspectos sociais e culturais do uso dos recursos florestais da Mata Atlântica. Pp. 135-158. In: L.L. Simões \& C.F. Lino (orgs.). Sustentável Mata Atlântica - A exploração de seus recursos florestais. São Paulo, Senac.

DPIW, 2007. Sphagnum moss - Sustainable use and management. Department of Primary Industries and Water of Tasmania, Australia. http://www.dpiw.tas.gov.au (Acesso em 05/02/2008).

Fantini, A.C.; Reis, A.; Reis, M.S.; Guerra, M.P. 1992. Susteined yield management in tropical forest: a proposal based on autoecology of the species. Sellowia 42-44: 25-33.

Gignac, L.D. \& Vitt, D.H. 1990. Habitat limitations of Sphagnum along climatic, chemical and physical gradients in mires of western Canada. The Bryologist 93:7-22. 
Gorham, E. \& Rochefort, L. 2003. Peatland restoration: A brief assessment with special reference to Sphagnum bogs. Wetlands Ecology and Management 11: 109-119.

Hayward; P. M. \& Clymo, R. S. 1983. The Growth of Sphagnum: Experiments on, and Simulation of, Some Effects of Light Flux and Water-Table Depth. The Journal of Ecology 71(3): 845-863.

Lamêgo, A. R. 1974. O Homem e a Restinga. 2a ed. Rio de Janeiro, Editora Lidador.

Lavoie C. \& Rochefort, L. 1996. The natural revegetation of a harvested peatland in southern Québec: A spatial and dendrocronological analysis. Écoscience 3:101-111.

Mello, L. G. 1995. Antropología cultural. Petrópolis, Editora Vozes.

Ming, L.C.; Silva, S.M.P.; Silva, M.A.S.; Hidalgo, A.F.; Marchese, J.A.; Chaves, F.C.M. 2003. Manejo e cultivo de plantas medicinais: algumas reflexões sobre perspectivas e necessidades no Brasil. Pp.149-156. In: M.F.B Coelho, P.C. Júnior, J.L.D. Dombroski (Org.). Diversos olhares em Etnobiologia, Etnoecologia e Plantas Medicinais. Cuiabá. Unicen. http://www.ufmt.br/etnoplan/artigos/Cultivo $\% 20 \mathrm{e} \% 20$ manejo $\% 20$ de $\% 20$ plantas\%20medicinais.PDF (acesso em 10/10/2007).

Neto, O. C. 2004. O trabalho de campo como descoberta e criação. Pp. 51-66. In: MINAYO, M. C. S. Pesquisa social: teoria, método e criatividade. Petrópolis, Editora Vozes.

Pfadenhauer, J. 1978. Contribuição ao conhecimento da vegetação e de suas condições de crescimento nas dunas costeiras do Rio Grande do Sul, Brasil. Revista Brasileira de Biologia 38: 827-836.

Rancura, S.A.O. 2009. Subsídios ao extrativismo de briófitas no município de Cananéia, São Paulo. Tese de Doutorado. Universidade Federal de São Carlos, UFSCar, São Carlos.

Rochefort, L. 2000. Sphagnum - A keystone genus in habitat restoration. The Bryologist 103:503-508.

Rochefort, L.; Campeau, S. \& Bugnon, J.L. 2002. Does prolonged flooding prevent or enhance regeneration and growth of Sphagnum? Aquatic Botany 74: 327-341.

Rojas, J.V. \& Schlatter, R. 2004. Las turberas de la Isla Chiloé (Xa Región, Chile): Aspectos sobre usos y estado de conservación. Pp. 86-92. In:
D.E. Blanco \& V.M. de la Balza (eds). Los turbales de la Patagonia, bases para su inventario y la conservación de su biodiversidad. Publicación $N^{\circ} 19$, Wetlands International, Buenos Aires, Argentina.

São Paulo. 1998. Portaria DEPRN n 52 de 28 de dezembro de 1998. Estabelece critérios para as licenças ambientais emitidas pelo Departamento Estadual de Proteção de Recursos Naturais. Diário Oficial do Estado de São Paulo. São Paulo.

Schlatter, R.P \& Schlatter. J.E. 2004. Los Turbales de Chile. Pp. 75-80. In: D.E. Blanco \& V.M. de la Balza (eds). Los turbales de la Patagonia, bases para su inventario y la conservación de su biodiversidad. Publicación $\mathrm{N}^{\circ} 19$, Wetlands International, Buenos Aires, Argentina.

Silva, S. M. 1999. Diagnóstico das Restingas no Brasil. In: Fundação BIO RIO, Workshop Avaliação e ações prioritárias para a conservação da biodiversidade na Zona Costeira e Marinha. Porto Seguro, Anais Eletrônicos. http://www.bdt.org.br/workshop/costa/Restinga. Acesso em $12 / 10 / 2008$.

Silveira, J.D. 1952. Baixadas litorâneas quentes e úmidas. Boletim da Faculdade de Filosofia, Ciências e Letras da Universidade de São Paulo (Série Botânica) 152:1-224.

Staddon, S. \& Dyke, A.J. 2007. Moss harvesting in Scottish forests: Its extent, value and sustainability. Scottish Forestry 63(1), 61-21.

Sugiyama, M. 1998. Estudo de florestas da restinga da Ilha do Cardoso, Cananéia, São Paulo, Brasil. Boletim do Instituto de Botânica 11: 119-159.

Tewari, D.D.; Campbell, J.Y. 1996. El auge de los productos florestales no madereros en la India. Unasylva 187(47): 26-31.

Viertler, R. B. 2002. Métodos Antropológicos como ferramenta para estudos em Etnobiologia e Etnoecologia. Pp 11-30. In: M. C. M. Amorozo, L. C.Ming \& S. P. Silva (Eds.). Métodos de coleta e Análise de dados em Etnobiologia, Etnoecologia e disciplinas correlatas - Anais do I Seminário de Etnobiologia e Etnoecologia do Sudeste. Rio Claro, Divisa Gráfica Editora.

Zar, J.H. 1996. Biostatiscal Analyses. 3rd Ed. Prentice-Hall International, Inc.

Versão eletrônica do artigo em www.scielo.br/abb e http://www.botanica.org.br/acta/ojs 